\title{
60-dB Bragg gratings in planar waveguides
}

\author{
Jouanno, Jean-Marc; Hübner, Jörg; Kristensen, M.
}

Published in:

Optical Fiber Communication. OFC 97., Conference on

Link to article, DOI:

10.1109/OFC.1997.719843

Publication date:

1997

Document Version

Publisher's PDF, also known as Version of record

Link back to DTU Orbit

Citation (APA):

Jouanno, J-M., Hübner, J., \& Kristensen, M. (1997). 60-dB Bragg gratings in planar waveguides. In Optical Fiber Communication. OFC 97., Conference on (pp. 228-229). IEEE. https://doi.org/10.1109/OFC.1997.719843

\section{General rights}

Copyright and moral rights for the publications made accessible in the public portal are retained by the authors and/or other copyright owners and it is a condition of accessing publications that users recognise and abide by the legal requirements associated with these rights.

- Users may download and print one copy of any publication from the public portal for the purpose of private study or research.

- You may not further distribute the material or use it for any profit-making activity or commercial gain

- You may freely distribute the URL identifying the publication in the public portal

If you believe that this document breaches copyright please contact us providing details, and we will remove access to the work immediately and investigate your claim. 
ever, receiver input power is estimated to be sufficiently high to realize $16 \times 16$ as well as $8 \times 8$.

In GDPC-SW with SM-to-MM combiner, power penalty due to amplified spontaneous emission (ASE) and coherent cross talk should be checked. We have carried out a 10-Gbit/s signal transmission experiment using the setup shown in Fig. 3(c). A 1550-nm optical signal is created by a distributed feedback laser-diode (DFB-LD) and a $\mathrm{LiNbO}_{3}$ modulator. Fiber-to-fiber gain of SOAGs is $8 \mathrm{~dB}$ at $25 \mathrm{~mA}$ injection current. The loss of 8:1 SM-to-MM combiner silica waveguide is $1.5 \mathrm{~dB}$. In the experiment, one of the two SOAGs was always in the on state and another was in the off state. Figure 3(a) shows a bit-error-rate (BER) curve. Power penalty due to ASE noise of the SOAG is estimated to be $<0.3 \mathrm{~dB}$. Degradation due to coherent cross talk was not observed in the BER measurement, because the extinction ratio of the SOAG was more than $50 \mathrm{~dB}$.

Figure 3(b) shows the signal waveform. The switching interval was $13 \mathrm{~ns}$ (128 bit). Turn-on-delay responses of SOAGs were compensated by simple electronics. ${ }^{2}$ As a result, the switching has been performed within $1 \mathrm{~ns}$.

As a conclusion, we have proposed a novel GDPC-SW that incorporates SOAGs and an SM-to-MM combiner, and demonstrated 10Gbit/s/port throughput, and 1-ns switching. We estimated that the switch can be extended up to $16 \times 16$ scale. This switch will remarkably improve the interconnection network performance in symmetric multiprocessor systems.

1. Y. Maeno et al., to be presented at MPPOI'96.

2. S. Takahashi et al., presented at PS'96, 1996, paper PThC1.

3. M. Gustavsson et al., Electron. Lett. 28, 2223-2225 (1992).

4. S. Kitamura et al., to be presented at ECOC'96.

5. I. Watanabe et al., in Optical Fiber Communication Conference and International Conference on Integrated Optics and Optical Fiber Communication, Vol. 4 of 1993 OSA Technical Digest Series (Optical Society of America, Washington, D.C., 1993) pp. 184-185.

\section{WL60}

\section{0-dB Bragg gratings in planar waveguides}

\author{
J.-M. Jouanno, J. Hübner, M. Kristensen, Mikroelektronik \\ Centret, Technical University of Denmark, Bldg. 345 East, \\ DK-2800 Lyngby, Denmark; E-mail:jmj@mic.dtu.dk
}

Bragg gratings are widely used as wavelength-selective elements in fiber devices. ${ }^{1}$ Integrated optics is a very attractive alternative for realizing such components. This way, multifunctional devices with high mechanical and thermal stability can be made using a technology with potential for mass-production. The main limitation until now was the quality of the gratings written in planar waveguides. We report here $60-\mathrm{dB}$ transmission dips obtained with 6-mm-long Bragg gratings written in Gedoped planar waveguides.

The waveguides have been made by depositing silica layers on silicon substrates by plasma-enhanced chemical vapor deposition (PECVD). The core dimensions are $6 \mu \mathrm{m} \times 6 \mu \mathrm{m}$ and the index step is $5.5 \cdot 10^{-3}$. The glass photosensitivity is enhanced by placing the waveguides in a deuterium chamber at high pressure for several days. ${ }^{2}$ Bragg gratings are then induced by illuminating the waveguides with UV light through a phase mask. ${ }^{3}$ The exposure was performed at $248 \mathrm{~nm}$ using a $\mathrm{KrF}$ excimer laser. The UV-beam intensity distribution was

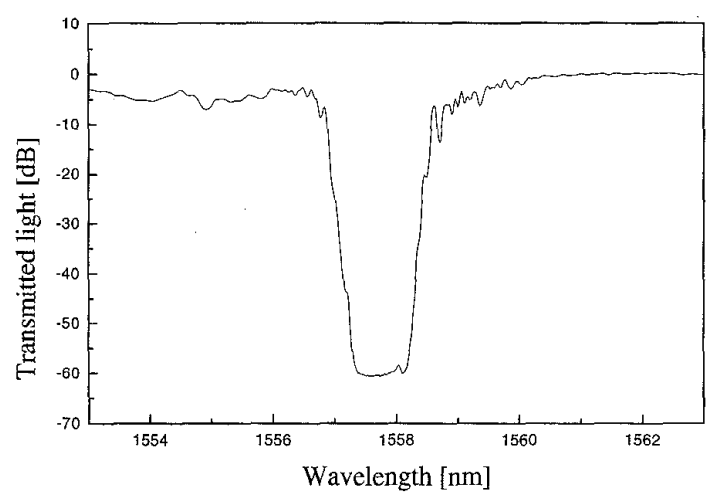

WL60 Fig. 1. Transmission spectrum of a 6-mm-long Bragg grating written in a planar waveguide.

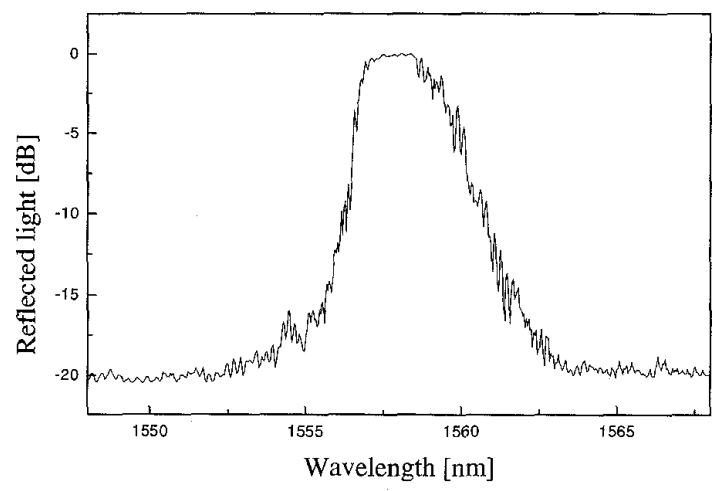

WL60 Fig. 2. Reflection spectrum of a 6-mm-long Bragg grating written in a planar waveguide.

approximately Gaussian leading to an apodization of the 6-mm-long gratings. The filter function was characterized by using amplified spontaneous emission (ASE) from an erbium-doped fiber pumped at 1480 $\mathrm{nm}$ as a light source. The spectra are recorded by an optical spectrum analyzer [Ando-AQ6315A].

The transmission spectrum is shown in Fig. $1.60 \mathrm{~dB}$ transmission dip has been measured indicating an index modulation higher than $9 \cdot 10^{-4}$. The measured transmission dip corresponds to the optical spectrum analyzer dynamic range. The filter function is, therefore, probably not fully resolved but the measured value represents, to the best of our knowledge, the strongest grating ever reported in planar waveguides.

The reflected spectrum is shown in Fig. 2. The 3-dB bandwidth is 2.6 $\mathrm{nm}$ and the sidelobe rejection is around $20 \mathrm{~dB}$.

The high-index modulation obtained in planar waveguides indicates that a variety of filter functions may be realized by changing the grating parameters. Moreover, for the same glass photosensitivity stronger filters may be written in planar waveguides than in optical fibers due to the geometry. In standard fibers, the distance between the phase mask and the core is indeed 62.5 micrometers while in planar waveguides the cladding layer thickness may be below 20 micrometers. Thus higher UV light visibility may be achieved and thereby a higher index modulation. ${ }^{4}$ 1. R. Kashyap in Proceedings of ECOC'95, 1995, paper Mo.A.3.1.

2. P.J. Lemaire, R.M. Atkins, V. Mizrahi, W.A. Reed, Electron. Lett. 29, 1191-1193 (1993). 
3. K.O. Hill, B. Malo, F. Bilodeau, D.C. Johnson, J. Albert, Appl. Phys. Lett. 62, 1035-1037 (1993).

4. J. Hübner, M. Svalgaard, N:. Kristensen, submitted to SPIE Photonics West 1997.

\section{WL61}

\section{New thermal stabilizing control of acousto-optic tunable filter using digital feedback technique}

Takeshi Fukuda, Ryouichi Watanabe, Masayuki Kashima, Hideaki Okayama,* Masato Kawahara, Kansai Laboratory, Oki Electric Industry Co., i.td., 1-2-27 Shirorni, Chuo-ku. Osaka-shi, 540 Japan; E-mail: rnabe@kansai.oki.co.jp

Tunable filter is one of the key clevices for the future wavelength-division multiplexing (WDM) system. The acousto-optic tunable filter (AOTF) has many advantages such as fast tuning speed and high resolution power. ${ }^{1}$ But, the selected wavelength by AOTF is varied by the influence of ambient temperature due to the temperature dependency of $\mathrm{LiNbO}_{3}$ as this device material. Therefore, there is a formerly stabilizing technique of AOTF by way of constant temperature control with Peltier elements. ${ }^{2}$ But, there are problems that the electric power consumed mainly by Peltier element and the scale of circuit become large in this way. We propose the new techrique of stabilizing control of AOTF using digital feedback technique.

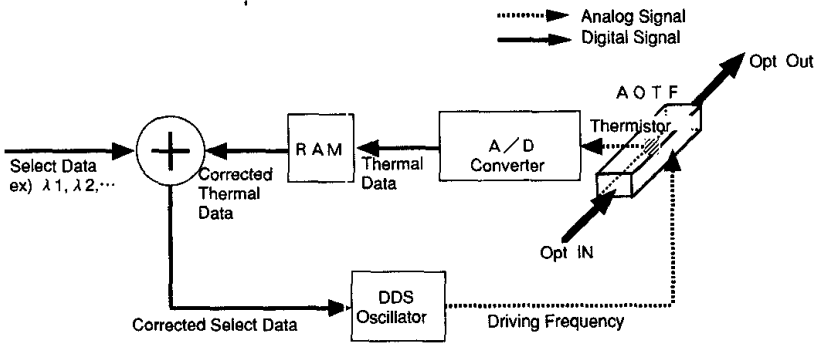

WL61 Fig. 1. Configuration of stabilizing circuit.

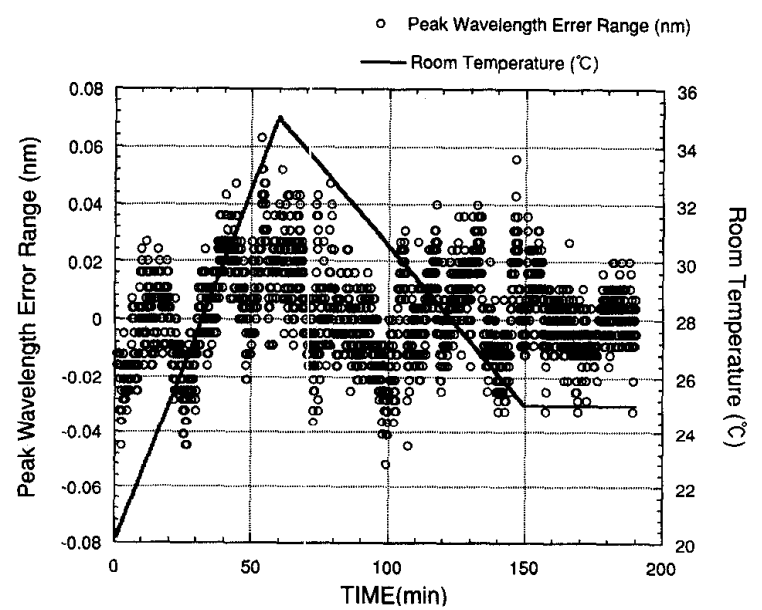

WL61 Fig. 2. Stability of wavelength control.

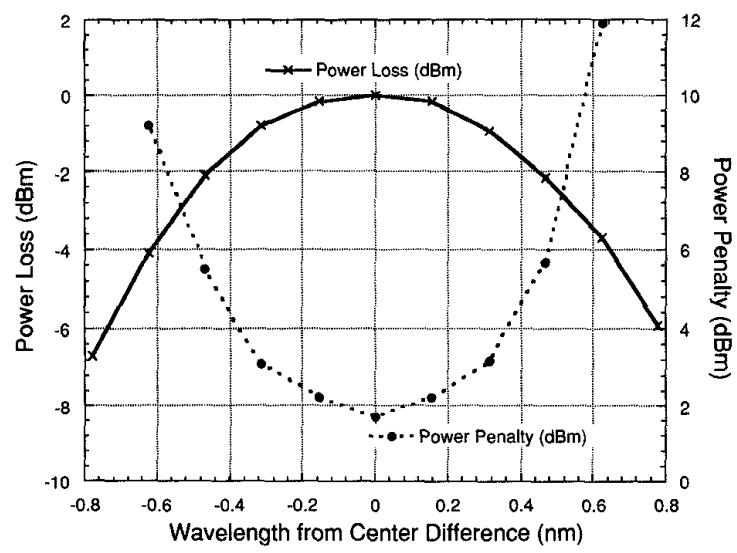

WL61 Fig. 3. Transmitting power and power penalty of AOTF.

We constructed the WDM network system of eight wavelength channels with channel separation of $3.2 \mathrm{~nm}$. In this system, the total stability of wavelength tuned by AOTF is necessarily under about $0.1 \mathrm{~nm}$. The configuration of our stabilizing circuit is shown in Fig. 1. To obtain the necessary wavelength stability, we use direct digital synthesizing (DDS) technique to generate the driving frequency of AOTF. Thermal data from thermister is A/D-converted, converted to the correction data stored in memory, added with the channel select signal and input into the digital input port of DDS oscillator.

By this controlling method, it became possible to reduce the electric power consumption and the circuit size. The satisfying stability of wavelength control under $\pm 0.065 \mathrm{~nm}$ was obtained in room temperature by our method as shown in Fig. 2. The power penalty that occurs on AOTF in the condition of the bit error rate $\angle 1 \mathrm{E}-10$ is shown in Fig. 3 and the bit rate of signal was $2.5 \mathrm{GHz}$. The reason for this power penalty depending on the deviation from the center wavelength of AOTF is now under investigation.

In spite of the influence of this power penalty, enough tunability of AOTF and enough signal-to-noise ratio were obtained by our new method using digital feedback technique.

* Semiconductor Technology Laboratory, Oki Electric Industry Co., Ltd.

1. David A. Smith et al., IEEE J. Commun. 8, (1990).

2. M.E. Winslow et al., IPR95 IFE4.

\section{WL62}

\section{Integration of polymer waveguide electro-optic modulators and VLSI electronics using standard lithographic fabrication techniques}

Srinath Kalluri, Mehrdad Ziari, William H. Steier, Larry R. Dalton,* Zaheed Karim,** Department of Electrical Engineering, University of Southern California, Los Angeles, California 90089-0483; E-mail: kalluri@scf.usc.edu

Over the last few years, electro-optic (EO) polymers have reached the state of technological maturity where devices for practical applications become feasible. For example, polymers with $\mathrm{EO}$ coefficients stable up to $300^{\circ} \mathrm{C}^{1}$ and $\mathrm{r}_{33}$ coefficients of $55 \mathrm{pm} / \mathrm{V}^{2}$ have been discovered recently. The ease with which polymers can be processed into multilayer devices by standard Si processing techniques makes them attractive for optoelec- 